\title{
Carbohydrate-Based Electron Donor for Biological Nitrate and Perchlorate Removal From Drinking Water
}

\author{
GIRIDHAR UPADHYAYA, ${ }^{1}$ NADINE KOTLARZ, ${ }^{2}$ PAUL TOGNA, ${ }^{3}$ AND LUTGARDE RASKIN²
}

\author{
${ }^{1}$ Carollo Engineers, Costa Mesa, Calif. \\ ${ }^{2}$ Department of Civil and Environmental Engineering, University of Michigan, Ann Arbor, Mich. \\ ${ }^{3}$ Independent consultant, Allentown, N.J.
}

This study evaluated the feasibility of replacing acetic acid with a commercial carbohydrate-based electron donor (CBED) for removal of nitrate and perchlorate $\left(\mathrm{ClO}_{4}^{-}\right)$from drinking water. Bench-scale biologically active carbon fixed-bed and fluidized-bed reactors (FXBR and FLBR, respectively), with an initial empty bed contact time (EBCT) of $42.8 \mathrm{~min}$, were fed simulated groundwater containing $15 \mathrm{mg} / \mathrm{L}$ nitrate as nitrogen and $200 \mu \mathrm{g} / \mathrm{L} \mathrm{ClO}_{4}{ }^{-}$. EBCT in the FLBR after final expansion was $80.5 \mathrm{~min}$. During the first
100 days using acetic acid at $125 \mathrm{mg} / \mathrm{L}$ chemical oxygen demand (COD), complete nitrate removal was achieved in both systems, whereas perchlorate in the FXBR and FLBR effluents remained below 3 and $6 \mu \mathrm{g} / \mathrm{L} \mathrm{ClO}_{4}^{-}$, respectively. For comparable removals, influent COD requirement was higher with the CBED. Biomass yields with acetic acid and the CBED were 0.54-0.58 and 0.59$0.74 \mathrm{mg} \mathrm{COD}{ }_{\text {biomass }} / \mathrm{mg} \mathrm{COD}$ substrate , respectively. The higher yield with the CBED resulted in more frequent maintenance requirements.

Keywords: biofilm, biological water treatment, contaminants, drinking water, fixed-bed reactor, fluidized-bed reactor

Nitrate $\left(\mathrm{NO}_{3}^{-}\right)$and perchlorate $\left(\mathrm{ClO}_{4}^{-}\right)$often coexist in drinking water sources (Li et al. 2010, Webster et al. 2009, Kimbrough \& Parekh 2007, Logan \& LaPoint 2002). Although nitrate is regulated in the United States at a maximum contaminant level (MCL) of $10 \mathrm{mg} / \mathrm{L}$ nitrate as nitrogen $\left(\mathrm{NO}_{3}{ }^{-}-\mathrm{N}\right)$, a federal drinking water regulation does not yet exist for perchlorate. Massachusetts and California have regulated perchlorate in drinking water with state-level MCLs of 2 and $6 \mu \mathrm{g} / \mathrm{L}$, respectively, and the proposed MCL in New Jersey is $5 \mu \mathrm{g} / \mathrm{L}$ (Water Research Foundation 2011). In addition, Arizona, California, Florida, Illinois, Iowa, Kansas, Maine, Maryland, Massachusetts, Nevada, New Jersey, New Mexico, New York, Oregon, Texas, and Vermont have adopted advisory levels ranging from 1 to $18 \mu \mathrm{g} / \mathrm{L} \mathrm{ClO}_{4}^{-}$(Water Research Foundation 2011). In 2008 the US Environmental Protection Agency (USEPA) issued an interim health advisory of $15 \mu \mathrm{g} / \mathrm{L}$ for perchlorate in drinking water (USEPA 2008). USEPA was expected to propose a federal drinking water standard for perchlorate in 2013 (USEPA 2011) at levels similar to the state MCLs, but a standard has not yet been proposed.

\section{BACKGROUND}

Biological treatment processes are effective for the removal of nitrate and perchlorate because microorganisms gain energy by mediating the reduction of these contaminants through denitrification and dissimilatory perchlorate reduction (Ricardo et al. 2012, Zhao et al. 2011, Li et al. 2010, Hamlin et al. 2008,
Brown et al. 2005, McCarty \& Meyer 2005). Advantages of biological treatment include the ability to remove many inorganic and organic contaminants simultaneously with minimal generation of waste products and without the requirement of regeneration of spent materials-e.g., ion exchange resins (Zhao et al. 2011, Li et al. 2010, Upadhyaya et al. 2010, Patel et al. 2008, Tziotzios et al. 2008, Fuller et al. 2007, Brown \& Lauderdale 2006). However, biological processes require the availability of an electron donor to provide the reducing equivalents to remove dissolved oxygen (DO), followed by denitrification and dissimilatory perchlorate reduction. Drinking water sources typically contain insufficient amounts of natural organic matter to support these processes, and thus biological treatment requires the addition of an electron donor such as acetate, ethanol, or hydrogen gas $\left(\mathrm{H}_{2}\right)$. This requirement makes it imperative to investigate the possibility of using alternative electron donors that could result in lower operating costs. When use of a new product is considered, it is essential to evaluate the product's effect on treatment performance, its required dose, and its suitability for drinking water treatment.

Methanol has been the most common supplemental electron donor to accomplish denitrification in water quality processes, especially in wastewater treatment (Ravnjak et al. 2013, MohseniBandpi \& Elliott 1998). However, its use is of concern because of its toxicity, volatility, and safety issues related to transportation, handling, and storage. As an alternative to methanol, electron donors such as glycerol, acetic acid, lactic acid, glucose, 
high-fructose corn syrup, hydrogen, and commercial products have been evaluated for their potential for biological denitrification in both wastewater and drinking water treatment applications (Bill et al. 2009, Cherchi et al. 2009, Pretorius et al. 2006, Akunna et al. 1993). Following its approval by NSF International for use in drinking water treatment, acetic acid has become a commonly used electron donor for biological treatment of drinking water (Li et al. 2010; Upadhyaya et al. 2010; Dugan et al. 2009; Webster et al. 2009; Brown et al. 2005, 2003). NSF International recently approved the use of a carbohydrate-based electron donor ${ }^{1}$ (CBED) - the commercial product evaluated in this research-for drinking water treatment (NSF International 2015). This product is delivered as an aqueous solution with approximately $680,000 \mathrm{mg} / \mathrm{L}$ chemical oxygen demand (COD). It has a specific gravity of 1.235 at $25^{\circ} \mathrm{C}$ and is yellowish in color with a $\mathrm{pH}$ of 3.75-4.25.

Biofilm reactors, such as fixed-bed reactors (FXBRs) and fluidized-bed reactors (FLBRs), allow the attainment of high concentrations of microbial biomass without the need for sludge recycling or biomass separation. As a result, high contaminant loading rates can be achieved in biofilm systems. Furthermore, these reactors are of particular importance when multiple contaminants coexist as microbial populations of different metabolic capabilities, positioned along the depth of the filter bed or throughout the biofilm, may use and subsequently remove the contaminants (Upadhyaya et al. 2010). However, owing to flow characteristics such as velocity, turbulence, and shear force, biofilm in an FXBR differs from that in an FLBR. In an FXBR, biofilm growth close to the inlet is expected to be greater and thicker than that near the outlet of the filter (Benthack et al. 2001, Rittmann 1982), with a spatial positioning of terminal electron accepting process (TEAP) zones along the filter depth (Upadhyaya et al. 2010). In contrast, biofilm of more uniform thickness is expected throughout an FLBR after maturation of the system (Rittmann 1982). The uniform biofilm observed in an FLBR may be attributed to high fluid shear and loss of particles caused by overexpansion and mixing of the attachment medium (Choi \& Silverstein 2007). The growth and characteristics of biofilm in turn affect the hydrodynamic behavior in the systems (Blanco et al. 1995) and may dictate the contaminant removal efficiency. Recirculating the effluent in an FXBR may result in better contaminant removal because of better distribution of biomass along the flow path (Choi \& Silverstein 2007). Several researchers have demonstrated the simultaneous removal of nitrate and perchlorate with FLBRs and FXBRs using $\mathrm{H}_{2}$ or acetic acid as the electron donor. For example, Kurt et al. (1987) and Webster et al. (2009) used $\mathrm{H}_{2}$ and acetic acid, respectively, as the electron donor in FLBRs. Similarly, Li et al. (2010) and Brown et al. (2005) used acetic acid as the elctron donor in FXBRs. Although a few research studies have compared the performance of FXBRs and FLBRs for wastewater treatment (Rezaee et al. 2011, Borja \& Banks 1995, Holladay et al. 1978), a systematic comparison of the performance of these systems has not been conducted for drinking water treatment.
The objective of the current study was to evaluate the feasibility of replacing acetic acid with the CBED in lab-scale bioreactors operated for the removal of nitrate and perchlorate from drinking water sources. Since both FXBRs and FLBRs are of interest in the drinking water field, this study evaluated the performance of both reactor configurations.

\section{MATERIALS AND METHODS}

Reactor setup and operation. Two lab-scale biologically active carbon (BAC) reactors-an FXBR system and an FLBR systemwere fabricated from glass columns with an inner diameter of $4.9 \mathrm{~cm}$ and heights of 56 and $50 \mathrm{~cm}$, respectively (Figure 1). The FLBR also had a 3-L spherical compartment (bowl) on top of the glass column. Both reactors were packed with granular activated carbon (GAC) particles ${ }^{2}$ (bituminous, 1.4-2.36 $\mathrm{mm}$ in size, bulk density of $0.69 \mathrm{~g} / \mathrm{cm}^{3}$ ) collected from a pilot-scale nitrate- and perchlorate-removing bioreactor ( $\mathrm{Li}$ et al. 2010) to attain a settled bed height of $34 \mathrm{~cm}$. Thus, the initial empty bed contact time (EBCT) in both reactors was $42.8 \mathrm{~min}$. The FXBR had $10 \mathrm{sam}-$ pling ports along the depth of the column.

The systems were inoculated with $15 \mathrm{~mL}$ of perchlorate-reducing culture $^{3}$ (Azospira suillum JPLRND). In addition, approximately $10 \mathrm{~g}$ of BAC, collected from a bench-scale system for nitrate and arsenic removal (Upadhyaya et al. 2010), was used to seed each reactor. To establish the microbial community in the filter beds, 5 gal of the influent (described subsequently) was recirculated at a flow rate of $1 \mathrm{~mL} / \mathrm{min}$ through the reactors for two days. The reactors were operated at $20.5 \pm 0.4^{\circ} \mathrm{C}$.

A synthetic groundwater was prepared representing the groundwater in Rialto, Calif. (Li et al. 2010), except that the perchlorate concentration selected was four times greater in order to simulate a groundwater with relatively high perchlorate contamination. Specifically, the synthetic groundwater contained approximately $7 \mathrm{mg} / \mathrm{L} \mathrm{DO}, 15 \mathrm{mg} / \mathrm{L} \mathrm{NO}_{3}{ }^{-}-\mathrm{N}, 12.5 \mathrm{mg} / \mathrm{L}$ sulfate $\left(\mathrm{SO}_{4}{ }^{2-}\right)$, and $200 \mu \mathrm{g} / \mathrm{L} \mathrm{ClO}_{4}{ }^{-}$along with other typical groundwater constituents (Table 1). A peristaltic pump was used to pump the influent through each reactor (downflow for the FXBR and upflow for the FLBR) at a flow rate of $15 \mathrm{~mL} / \mathrm{min}$ (Figure 1). The influent to the FLBR was introduced in the recirculation line, which was operated at a flow rate of $1.8 \mathrm{~L} / \mathrm{min}$ using a peristaltic pump to achieve an initial bed expansion of $29 \%$ (i.e., expanded bed height $=44 \mathrm{~cm}$ ). This flow rate resulted in a final steady-state bed expansion (i.e., after the development of biofilm) of $88 \%$ (bed height $=64 \mathrm{~cm}$ ) because of the growth of biofilm on the GAC particles. Although the initial EBCT was $42.8 \mathrm{~min}$ in both the FXBR and unexpanded FLBR, the final EBCT in the FLBR under steady-state conditions was $80.5 \mathrm{~min}$.

A peristaltic pump was used to pump the electron donor from a concentrated stock at a flow rate of $0.17 \mathrm{~mL} / \mathrm{min}$ to achieve the calculated final concentration. Acetic acid was used as the electron donor for the first 100 days of reactor operation; subsequently, the CBED was used as the electron donor. On the basis of a typical net biomass yield of $0.4 \mathrm{~g} \mathrm{COD}_{\text {biomass }} / \mathrm{g} \mathrm{COD}$ acetate (Rittmann \& McCarty 2001), 83 mg/L COD to be required to completely remove the DO, nitrate, and perchlorate present in the influent. With a safety factor of 1.5 , the 
FIGURE 1 Schematic presentation of the FXBR and FLBR setup

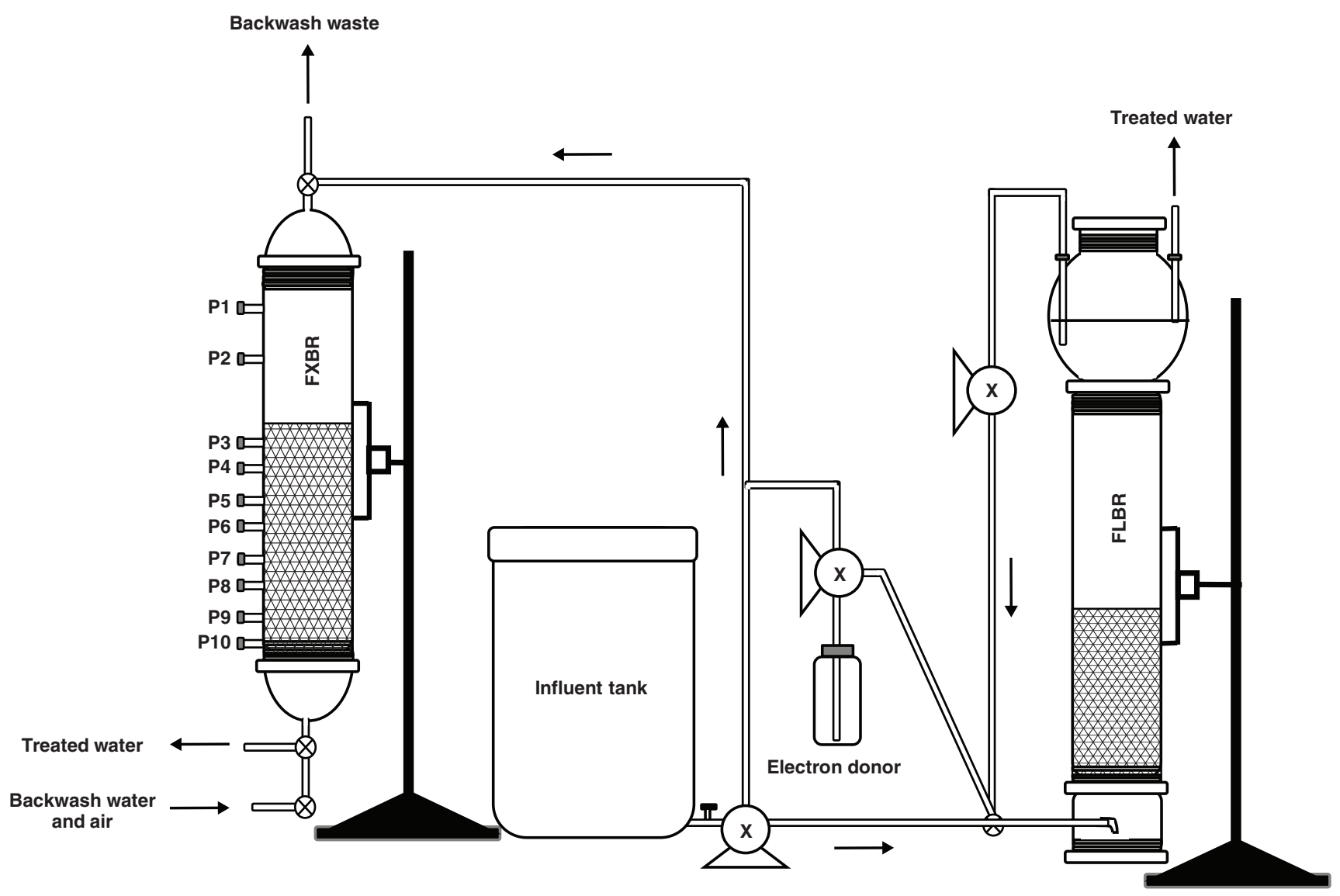

FLBR—fluidized-bed reactor, FXBR—fixed-bed reactor, P-port

TABLE 1 Chemical composition of the synthetic groundwater

\begin{tabular}{|c|c|c|c|}
\hline Chemicals Used & Ions & Expressed as & $\begin{array}{c}\text { Concentration } \\
m g / L\end{array}$ \\
\hline $\mathrm{NaNO}_{3}$ & $\mathrm{NO}_{3}^{-}$ & $\mathrm{N}$ & $10.2-19.7$ \\
\hline$\underset{\text { and } \mathrm{CaCl}_{2}}{\mathrm{NaCl} \mathrm{MgCl}_{2}} \cdot 6 \mathrm{H}_{2} \mathrm{O}$, & $\mathrm{Cl}^{-}$ & $\mathrm{Cl}^{-}$ & $25.5-50.8$ \\
\hline $\mathrm{K}_{2} \mathrm{CO}_{3}$ & $\mathrm{CO}_{3}{ }^{2-}$ & $\mathrm{CO}_{3}^{2-}$ & $6^{\mathrm{a}}$ \\
\hline $\mathrm{NaHCO}_{3}$ & $\mathrm{HCO}_{3}^{-}$ & $\mathrm{HCO}_{3}^{-}$ & $213.5^{a}$ \\
\hline $\mathrm{Na}_{2} \mathrm{SO}_{4}$ & $\mathrm{SO}_{4}^{2-}$ & $\mathrm{SO}_{4}^{2-}$ & $9.3-16.8$ \\
\hline $\mathrm{NaClO}_{4}$ & $\mathrm{ClO}_{4}^{-}$ & $\mathrm{ClO}_{4}^{-}$ & 0.2 \\
\hline $\mathrm{KH}_{2} \mathrm{PO}_{4}$ & $\mathrm{PO}_{4}^{3-}$ & $P$ & 0.5 \\
\hline
\end{tabular}

$\mathrm{CaCl}_{2}$-calcium chloride, $\mathrm{Cl}^{-}$- chloride, $\mathrm{ClO}_{4}^{-}$- perchlorate, $\mathrm{CO}_{3}{ }^{2-}$-carbonate, $\mathrm{HCO}_{3}{ }^{-}-$ bicarbonate, $\mathrm{K}_{2} \mathrm{CO}_{3}$ - potassium carbonate, $\mathrm{KH}_{2} \mathrm{PO}_{4}$ - monopotassium phosphate, $\mathrm{MgCl}_{2} \bullet 6 \mathrm{H}_{2} \mathrm{O}$-magnesium chloride hexahydrate, $\mathrm{N}$-nitrogen, $\mathrm{NaCl}$-sodium chloride, $\mathrm{NaClO}_{4}$ - sodium perchlorate, $\mathrm{NaHCO}_{3}$ - sodium bicarbonate, $\mathrm{NaNO}_{3}$ - sodium nitrate, $\mathrm{Na}_{2} \mathrm{SO}_{4}$ - sodium sulfate, $\mathrm{NO}_{3}{ }^{-}$-nitrate, $\mathrm{P}$ - phosphorus, $\mathrm{PO}_{4}{ }^{3-}$ - phosphate, $\mathrm{SO}_{4}{ }^{2-}$ - sulfate

${ }^{a}$ Determined on the basis of the amount of chemical used to prepare the influent influent COD concentration was maintained at $125 \mathrm{mg} / \mathrm{L}$ acetate COD for the first 100 days of reactor operation. From day 101 to day 152, the CBED was used as the electron donor with an influent COD level of $125 \mathrm{mg} / \mathrm{L}$ COD. The influent COD concentration was subsequently adjusted to 250,165 , and $150 \mathrm{mg} / \mathrm{L}$ CBED COD on days 153, 166, and 198, respectively.

The FXBR was backwashed every other day with a mixed flow of compressed air and deionized (DI) water $(50 \mathrm{~mL} / \mathrm{min})$ to completely fluidize the filter bed for $3 \mathrm{~min}$, followed by a flow of DI water $(500 \mathrm{~mL} / \mathrm{min})$ for $4 \mathrm{~min}$ to remove the dislodged biomass. Every week the liquid in the bowl of the FLBR was stirred manually to resuspend the sludge deposited on the sides of the bowl, and approximately $1 \mathrm{~L}$ was wasted. After the system was operated with the CBED for 54 days (starting on day 155), the FXBR was backwashed daily and the flushing flow of $500 \mathrm{~mL} / \mathrm{min}$ was changed to $\sim 300 \mathrm{~mL} / \mathrm{min}$; the bowl of the FLBR was stirred every three to four days before biomass was wasted.

Liquid sample collection and chemical analyses. Liquid samples were collected from the influent tank and the effluents of both reactors at regular intervals, typically every three to four days. In addition, liquid profile samples were collected from the 
sampling ports along the depth of the FXBR on days 78 and 196. All liquid samples were filtered through 0.22 - $\mu \mathrm{m}$ filters, ${ }^{4}$ stored at $4^{\circ} \mathrm{C}$, and subsequently analyzed for acetate, nitrate, chloride, sulfate, perchlorate, soluble COD (sCOD), and nonpurgeable organic carbon (NPOC).

DO levels in the influent were measured in the influent tank using a multipurpose meter ${ }^{5}$ (detection limit of $0.01 \mathrm{mg} / \mathrm{L}$ ). Redox potentials in the effluents were measured in flow-through cells using a $\mathrm{pH}$ meter $^{6}$ fitted with an oxidation-reduction (redox) potential (ORP) electrode. The $\mathrm{pH}$ of the influent and effluent samples was determined using a portable $\mathrm{pH}$ meter. ${ }^{7}$

Acetate, nitrate, chloride, sulfate, and perchlorate in liquid samples were measured using an ion chromatography system with a conductivity detector. 8 The anions were chromatographically separated using an anion exchange column ${ }^{9}$ fitted with a capillary guard column. ${ }^{10}$ To elute the anions through the column, the researchers used a gradient flow of potassium hydroxide (0-13 min, increasing gradually from 12 to $52 \mathrm{mM}$; 13-22 min at $52 \mathrm{mM}$; and 22-30 $\mathrm{min}$ at $12 \mathrm{mM}$ ). The detection limits for acetate, chloride, nitrate, sulfate, and perchlorate were $0.1 \mathrm{mg} / \mathrm{L}, 0.04 \mathrm{mg} / \mathrm{L}$, $0.05 \mathrm{mg} / \mathrm{L}, 0.04 \mathrm{mg} / \mathrm{L}$, and $3 \mu \mathrm{g} / \mathrm{L}$, respectively. NPOC was measured in liquid samples using a total organic carbon analyzer. ${ }^{11}$ Inorganic carbon was removed through acidification of the samples using the function available in the analyzer for NPOC analysis. The detection limit for NPOC was $0.3 \mathrm{mg} / \mathrm{L} \mathrm{C}$. The sCOD was determined using the COD microdigestion method (Hach 2014) and a spectrophotometer $^{12}$ by measuring absorbance at $420 \mathrm{~nm}$. The method detection limit for sCOD was $3.7 \mathrm{mg} / \mathrm{L}$.

Yield determination. Biomass yields were estimated using Eqs 1 and 2:

biomass COD = influent COD - effluent COD

- theoretical COD required for the electron acceptors

yield $=($ biomass COD $) /($ influent COD - effluent COD $)$

To determine the COD requirements for the electron acceptors, COD equivalents of $2.86 \mathrm{mg} \mathrm{COD} / \mathrm{mg} \mathrm{NO}_{3}{ }^{-} \mathrm{N}$ and $0.67 \mathrm{mg}$ $\mathrm{COD} / \mathrm{mg} \mathrm{ClO}_{4}{ }^{-}$were used for $\mathrm{NO}_{3}{ }^{-} \mathrm{N}$ and $\mathrm{ClO}_{4}{ }^{-}$, respectively.

\section{RESULTS}

Reactor performance. When acetic acid was used as the electron donor, nitrate and perchlorate removals were established in both reactors after a startup period of approximately 20 days (data not shown). Figure 2 shows performance data for the final period of using acetic acid as the electron donor (days 75-100). For this operating period, the $\mathrm{pH}$ and $\mathrm{DO}$ in the influents (samples collected from ports upstream of the electron donor injection location) were $8.6 \pm 0.2$ (mean \pm standard deviation) and $7.7 \pm 0.7 \mathrm{mg} / \mathrm{L}$, respectively; $\mathrm{pH}$ values of the effluents of the FXBR $(7.4 \pm 0.3)$ and the FLBR $(7.3 \pm 0.3)$ were not significantly different $(p>0.05)$. DO levels in the effluents were $<0.02 \mathrm{mg} / \mathrm{L}$ at all times. ORP was a reliable indicator of reactor performance and correlated well with nitrate and perchlorate concentration trends in the effluents (Figure 2). Typically, ORP levels lower than $-300 \mathrm{mV}$ were observed when complete nitrate removal and $>180 \mu \mathrm{g} / \mathrm{L}$ perchlorate removal were observed. In general, an ORP lower than $-250 \mathrm{mV}$ was observed when sulfate reduction was established in the systems.

Influent nitrate levels averaged $13.1 \pm 2.1 \mathrm{mg} / \mathrm{L} \mathrm{NO}_{3}{ }^{-} \mathrm{N}$ from days 75-100, and complete nitrate removal was achieved in both reactors (Figure 2). Influent perchlorate levels averaged $201.1 \pm 16.9 \mu \mathrm{g} / \mathrm{L}$ during this period, and effluent perchlorate levels were always below detection $(3 \mu \mathrm{g} / \mathrm{L})$ for the FXBR and $<6 \mu \mathrm{g} / \mathrm{L}$ for the FLBR. The acetate COD in the FXBR and FLBR effluents (calculated from the acetate concentrations measured by ion chromatography) closely matched the less frequently measured effluent sCOD concentrations (Figure 3 ) and averaged $18.8 \pm 7.4$ and $17.0 \pm 8.2 \mathrm{mg} / \mathrm{L}$, respectively.

Acetic acid was replaced with the CBED on day 100. During days 101-129, the influent nitrate concentration averaged 11.2 $\pm 0.1 \mathrm{mg} / \mathrm{L} \mathrm{NO}_{3}{ }^{-}-\mathrm{N}$. On and beyond day 130 , the influent nitrate level was readjusted to the target level of $15 \mathrm{mg} / \mathrm{L} \mathrm{NO}_{3}{ }^{-} \mathrm{N}$ and was measured to average $14.9 \pm 1.2 \mathrm{mg} / \mathrm{L} \mathrm{NO}_{3}{ }^{-}-\mathrm{N}$ during days 130-154 (Figure 2). Complete nitrate removal was achieved until day 125 , but the effluents contained measurable nitrate levels beyond day 126. Specifically, from day 130 to 152, the FXBR and FLBR effluent nitrate levels averaged $0.4 \pm 0.6$ and $0.8 \pm 1.0 \mathrm{mg} / \mathrm{L}$ $\mathrm{NO}_{3}{ }^{-}-\mathrm{N}$, respectively. After the switch to the CBED on day 100 , effluent perchlorate concentrations increased gradually in both reactors and on day 152 reached $136 \mu \mathrm{g} / \mathrm{L}$ in the FXBR and 160 $\mu \mathrm{g} / \mathrm{L}$ in the FLBR (Figure 2). During days 101-130, the acetate COD in the FXBR and FLBR effluents averaged $12.7 \pm 8.5$ and $8.0 \pm 3.7 \mathrm{mg} / \mathrm{L}$, respectively. However, the higher influent nitrate levels after day 130 resulted in lower effluent acetate concentrations (Figure 3), suggesting that insufficient COD was being supplied during this period. Specifically, from days 130-152, the NPOC in the FXBR and FLBR effluents averaged $1.5 \pm 0.3$ and $1.1 \pm 0.2$, respectively, whereas effluent acetate COD was below detection (Figure 3).

After influent COD levels were increased to $250 \mathrm{mg} / \mathrm{L}$ on day 153 , complete nitrate removal was reestablished, and effluent perchlorate levels were similar to those observed during the period with acetic acid as the electron donor. Effluent nitrate and perchlorate levels remained the same even after influent COD was lowered to $165 \mathrm{mg} / \mathrm{L}$ on day 166 . However, significant sulfate reduction was also observed, especially in the FLBR (Figure 2), indicating that this level of COD dosing was more than needed for complete nitrate and perchlorate reduction. To minimize sulfate reduction, the influent COD was lowered to $150 \mathrm{mg} / \mathrm{L}$ on day 198, which negatively affected nitrate and perchlorate removals, with a more pronounced effect on the FLBR (Figure 2). Effluent COD levels were consistent with these observations, but acetate was detected. Effluent acetate COD levels for the FXBR and FLBR were $36.5 \pm 24.8$ and $35.7 \pm 24.1 \mathrm{mg} / \mathrm{L}$, respectively, during days $153-166 ; 20.8 \pm 18.7$ and $7.3 \pm 13.8 \mathrm{mg} / \mathrm{L}$, respectively, during days 167-197; and $3.1 \pm 2.4$ and $0 \mathrm{mg} / \mathrm{L}$, respectively, during days 198-215 (Figure 3).

Visual observations suggested a shift in biomass characteristics in both systems after the CBED was used as the electron donor. The liquid in the bowl of the FLBR system became cloudier, and 
FIGURE 2 Influent and FXBR and FLBR effluent nitrate, perchlorate, and sulfate concentrations and ORP

$\diamond$ Influent $\quad \triangle$ FXBR effluent $\quad$ FLBR effluent

\begin{tabular}{|c|c|c|c|c|}
\hline \multicolumn{2}{|c|}{ Acetic Acid } & \multicolumn{3}{|l|}{ CBED } \\
\hline COD—mg/L & 125 & 250 & 165 & 150 \\
\hline
\end{tabular}
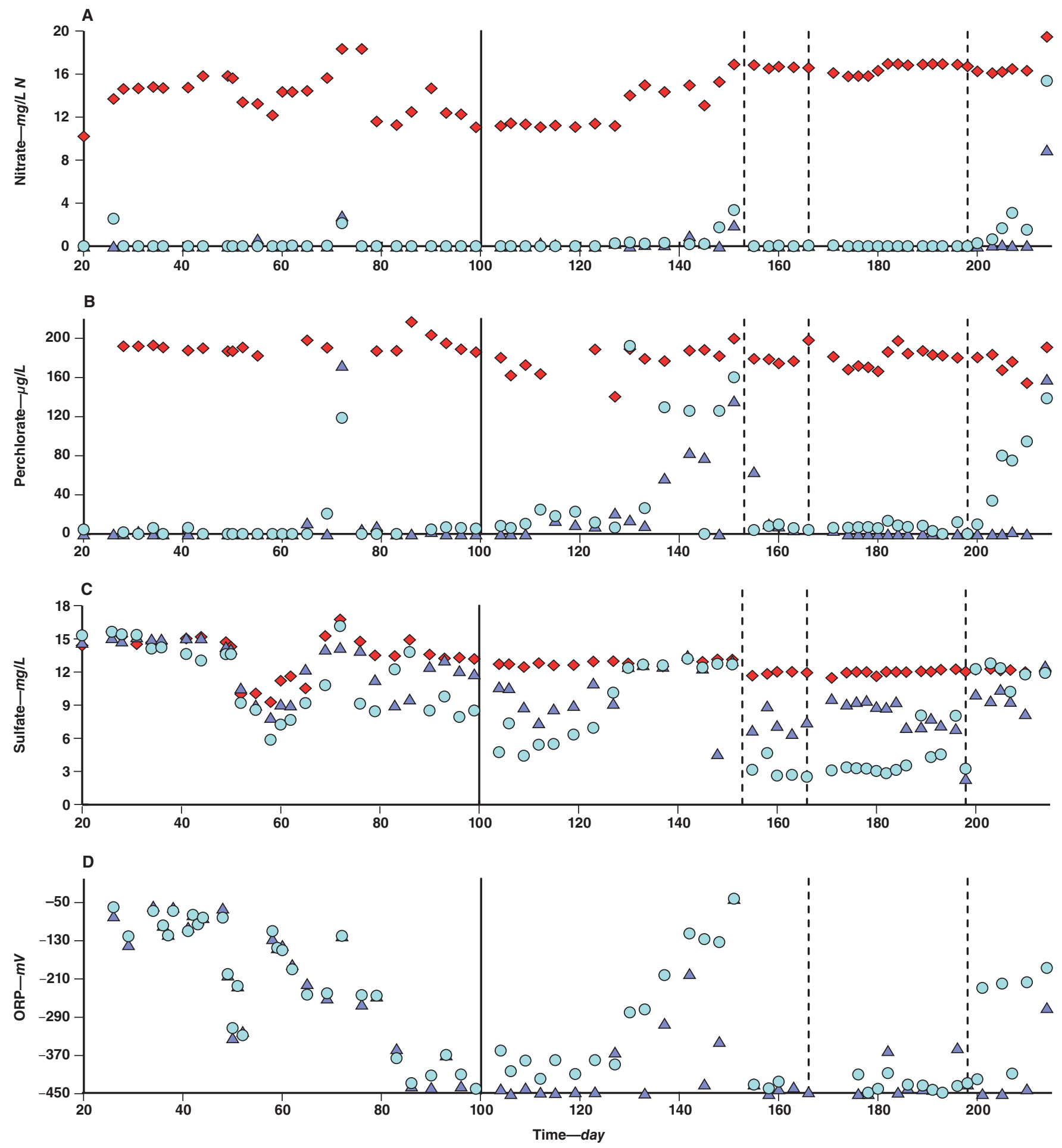

CBED—carbohydrate-based electron donor, COD—chemical oxygen demand, FLBR—fluidized-bed reactor, FXBR-fixed-bed reactor, ORP-oxidation-reduction (redox) potential 
FIGURE 3 Soluble COD in the influent and effluents of the FXBR and FLBR

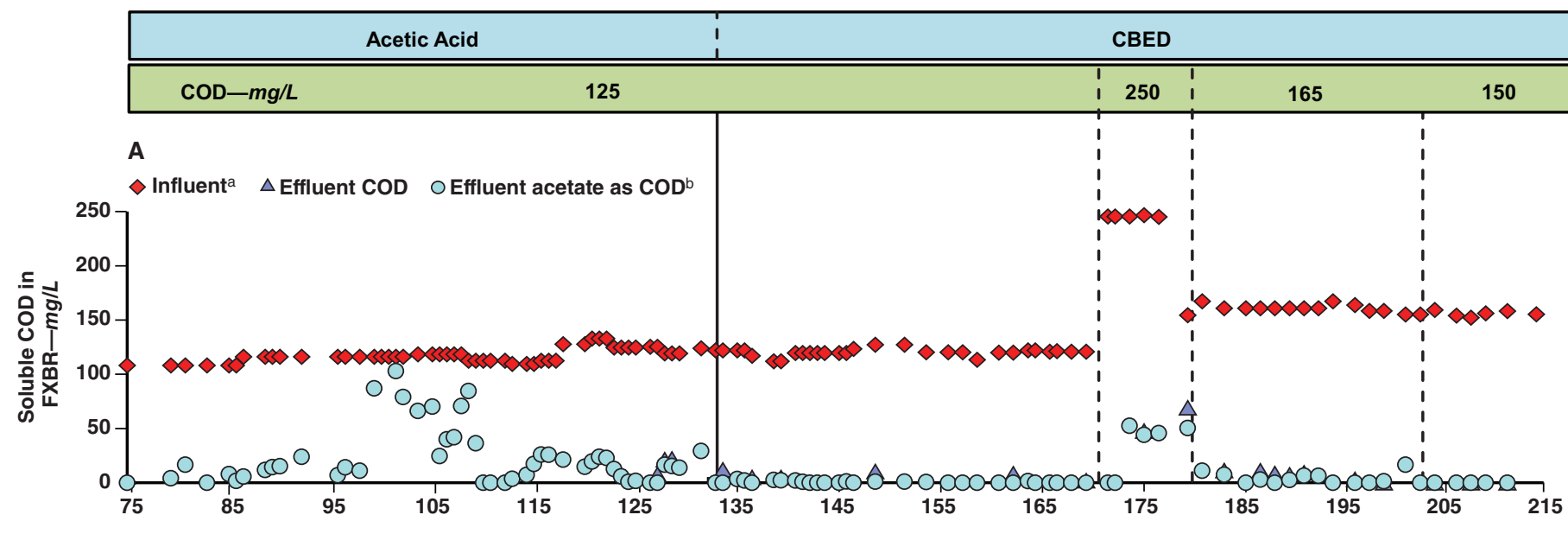

B

$\triangle$ Effluent NPOC $\bigcirc$ Effluent acetate as C

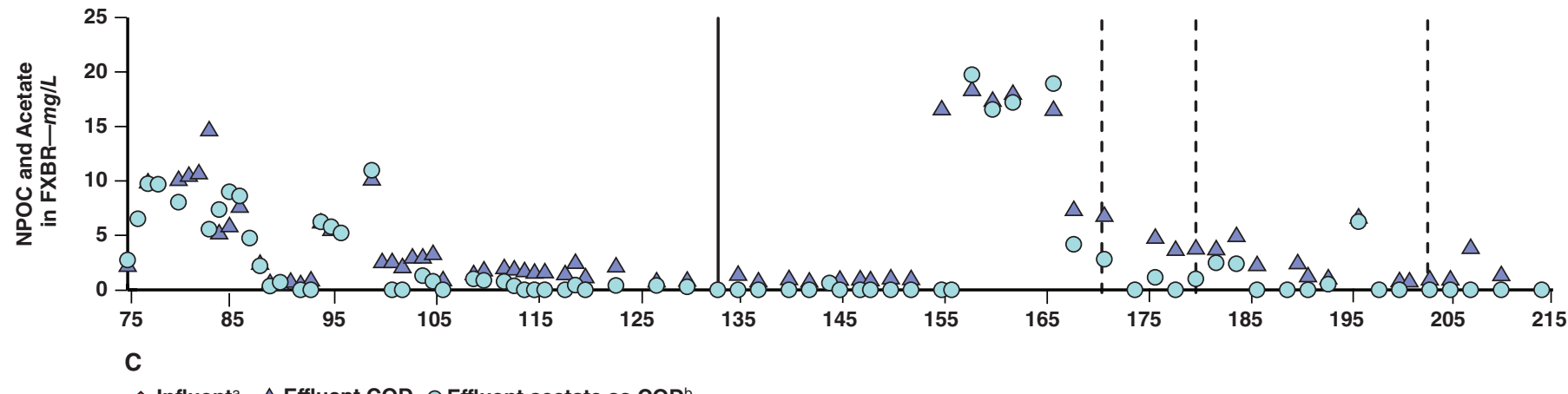

$\diamond$ Influent $^{\mathrm{a}} \quad \triangle$ Effluent COD $\bigcirc$ Effluent acetate as COD $^{\mathrm{b}}$

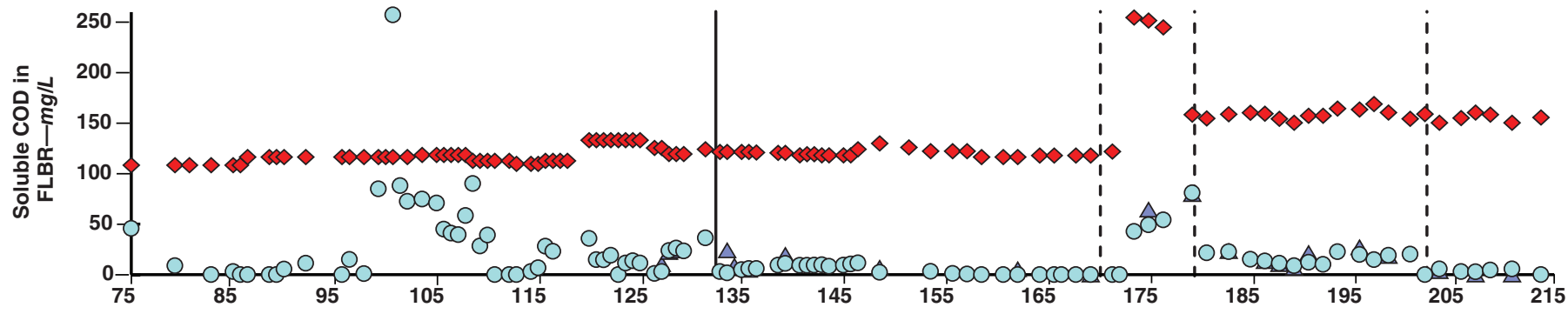

D

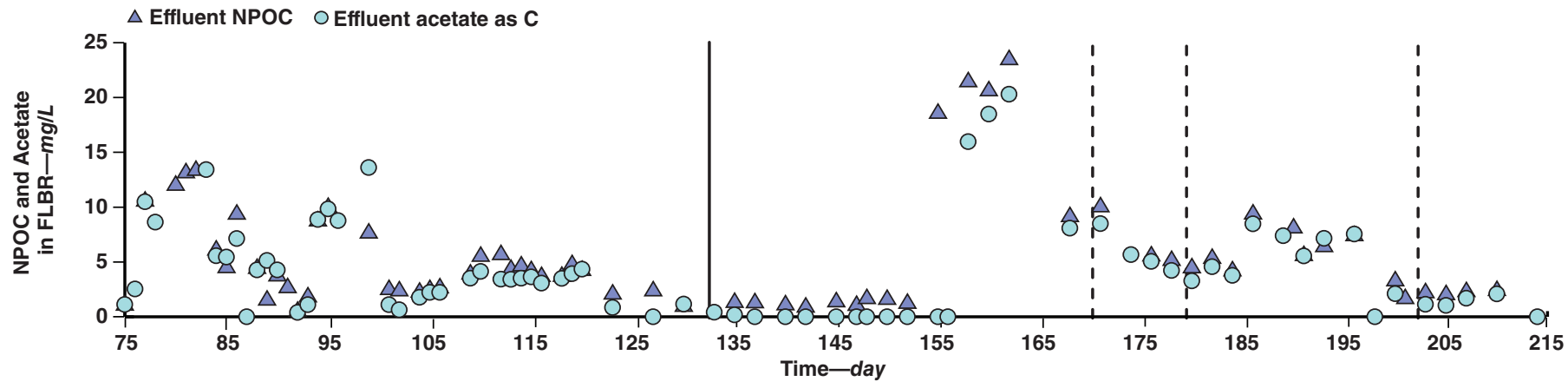

C—carbon, CBED—carbohydrate-based electron donor, COD—chemical oxygen demand, FLBR—fluidized-bed reactor, FXBR—fixed-bed reactor, NPOC-nonpurgeable organic carbon

anfluent COD was estimated from flow rate and the electron donor concentrations in the stock.

${ }^{b}$ Effluent acetate COD was derived from effluent acetate concentrations. 


\begin{tabular}{|c|c|c|}
\hline Biomass yie & differe & nditions \\
\hline \multirow[b]{2}{*}{ Electron Donor Used } & \multicolumn{2}{|c|}{$\begin{array}{c}\text { Estimated Yield } \\
m g C O D_{\text {biomass }} / m g C O D_{\text {substrate }}\end{array}$} \\
\hline & FXBF & FLBR \\
\hline Acetic acid-125 mg/L COD & 0.58 & 0.54 \\
\hline CBED-125 mg/L COD & 0.63 & 0.59 \\
\hline CBED-250 mg/L COD & 0.74 & 0.69 \\
\hline CBED-165 mg/L COD & 0.60 & 0.61 \\
\hline CBED $-150 \mathrm{mg} / \mathrm{L} \mathrm{COD}$ & 0.61 & 0.64 \\
\hline
\end{tabular}

progressively more biomass was deposited on the sides of the bowl, resulting in the need to remove biomass more frequently. The GAC particles in the FXBR system were gradually coated with more and thicker cotton-like biofilm. This development had two consequences: first, the BAC bed became more tightly packed, which required more frequent backwashing, and second, the BAC particles became lighter, leading to the requirement of a lower flushing flow rate (i.e., $300 \mathrm{~mL} / \mathrm{min}$ versus $500 \mathrm{~mL} / \mathrm{min}$ ) during backwashing. This observation of increased biomass growth was supported by the calculated yields. During the period with acetic acid, the yields ranged from 0.54 to $0.58 \mathrm{mg} \mathrm{COD}$ biomass $/ \mathrm{mg}$ $\mathrm{COD}_{\text {substrate }}$, whereas the yields ranged from 0.59 to $0.74 \mathrm{mg}$ $\mathrm{COD}_{\text {biomass }} / \mathrm{mg} \mathrm{COD}$ substrate when the CBED was used as the electron donor (Table 2).

Concentration profiles along the depth of the FXBR. Samples were collected along the depth of the FXBR filter on days 78 and 196 to characterize TEAP zones during the use of acetate and the

FIGURE 4 Concentration profiles along the depth of the FXBR

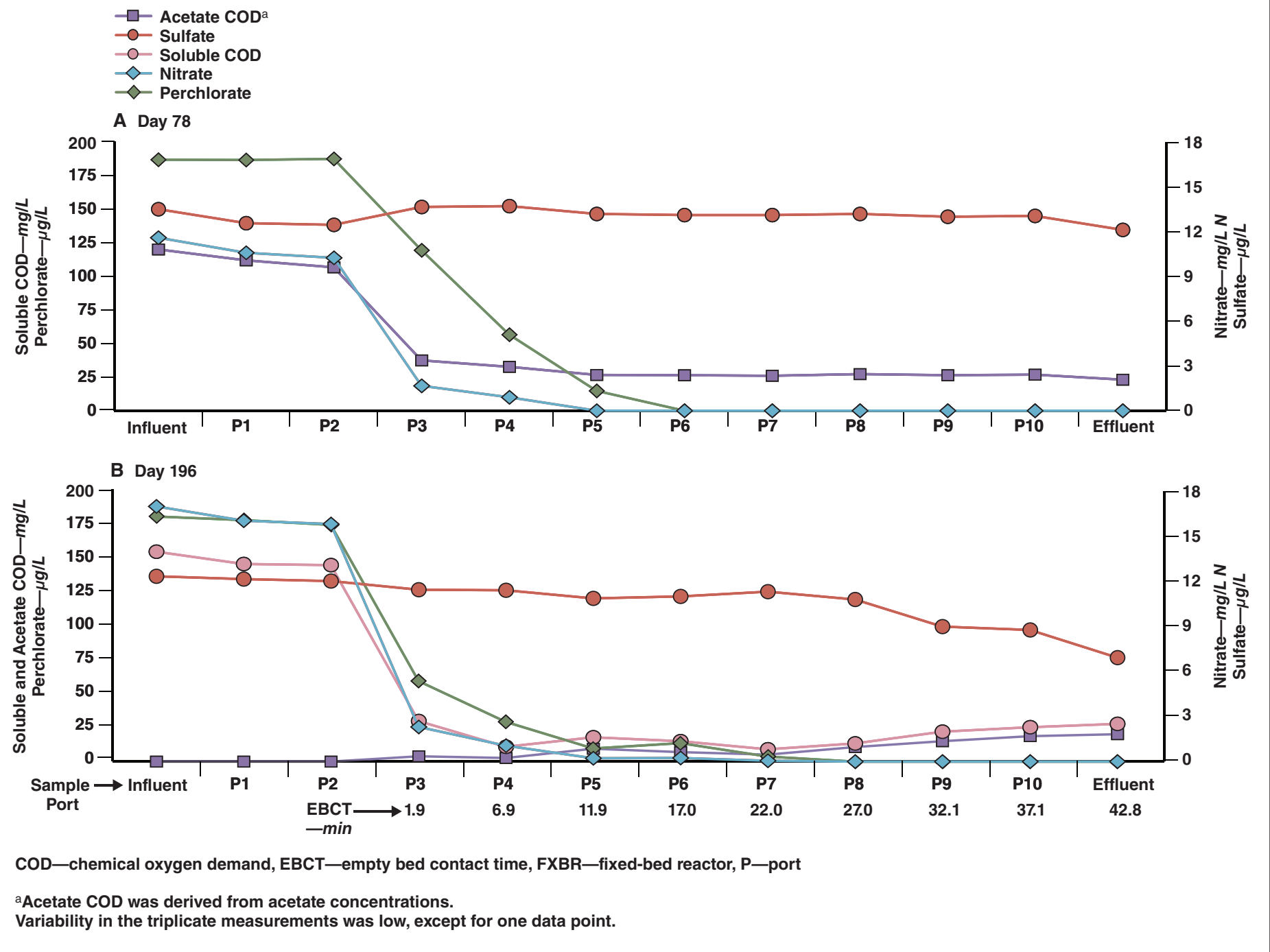




\section{FIGURE 5 Chloride, nitrate, perchlorate, sulfate, and COD} concentrations on day 203 before and after the backwash
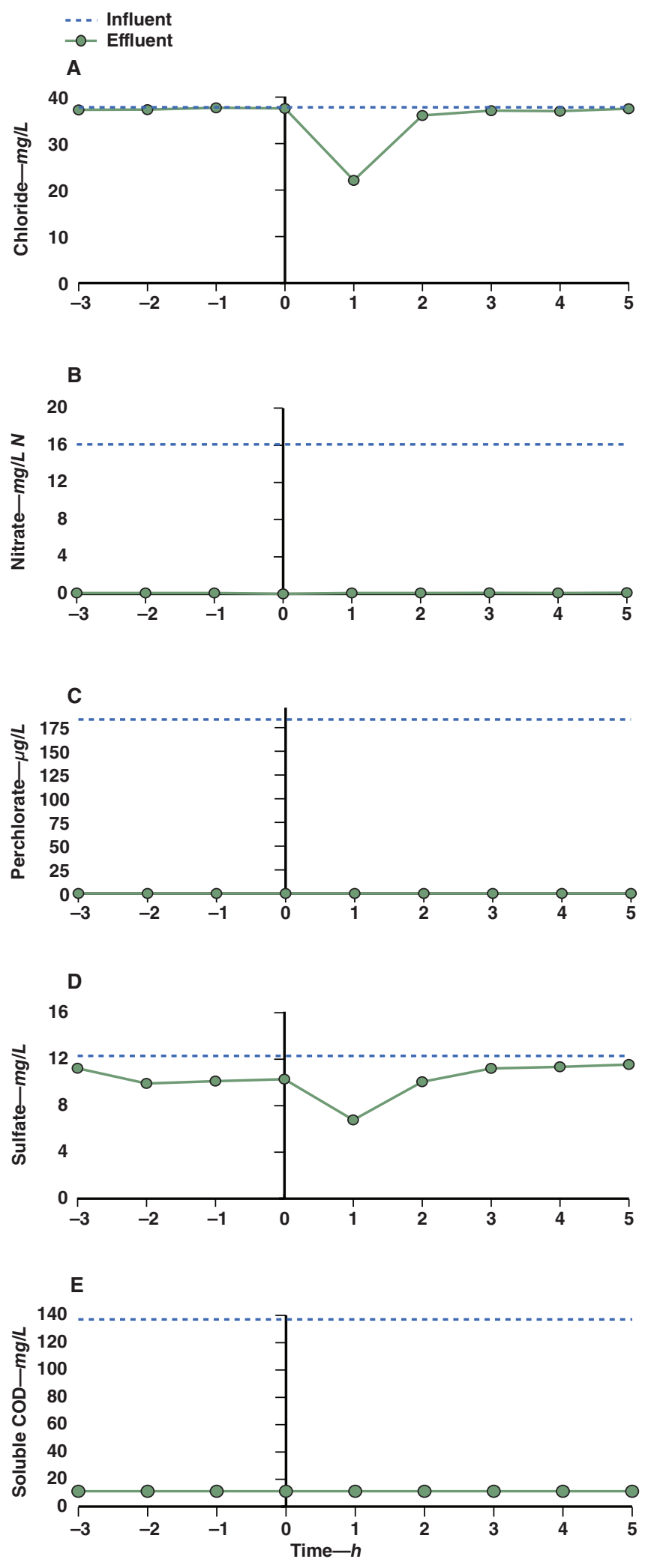

COD—chemical oxygen demand
CBED, respectively. The profile data collected on day 78 (Figure 4, part A) indicated that nitrate reduction took place in the upper part of the bed, resulting in a nitrate level below the detection limit of $0.04 \mathrm{mg} / \mathrm{L}$ at sampling port P5 (corresponding to an EBCT of 9.5 min). Similarly, perchlorate removal took place in the upper part of the bed and was complete before port P6 (EBCT of $13.5 \mathrm{~min}$ ). Sulfate reduction was very limited throughout the bed. The COD concentration profile corresponded well with the reduction of the electron acceptor; the highest COD consumption was observed between ports $\mathrm{P} 2$ and $\mathrm{P} 3$, where most of the nitrate and perchlorate reduction occurred.

The chemical profiles collected on day 196 (Figure 4, part B) reflected the trends observed on day 78 -i.e., most nitrate, perchlorate, and COD removal occurred between ports P2 and P3. However, nitrate and perchlorate removal were complete only at ports P7 (EBCT of $17.5 \mathrm{~min}$ ) and P8 (EBCT of 21.5 min), respectively. Sulfate reduction also ensued beyond port $\mathrm{P} 3$, and the rate of sulfate reduction was greatest after nitrate and perchlorate were removed. The sCOD increased after port $\mathrm{P} 4$, mapping the increase in acetate COD (calculated from the measured acetate concentrations).

Effect of backwashing on FXBR performance. Hourly effluent samples collected before and immediately after backwashing the FXBR on day 203 indicated that effluent nitrate and perchlorate concentrations were below detection in all cases (Figure 5), suggesting that nitrate and perchlorate removals were not affected by backwashing. Chloride and sulfate concentrations in the sample collected $1 \mathrm{~h}$ after backwashing were slightly lower than the concentrations in the other samples because of a dilution effect. Paired $t$-test results suggested that the effluent concentrations of chloride, sulfate, and acetate before and after the backwashing (excluding the data collected $1 \mathrm{~h}$ after backwashing) were not significantly different ( $p>0.05$ for all analytes).

\section{DISCUSSION}

As previously reported, complete removal of $25 \mathrm{mg} / \mathrm{L}$ nitrate and $75 \mu \mathrm{g} / \mathrm{L}$ perchlorate can be achieved in an FXBR with an EBCT of 20 min using acetic acid as the electron donor (Li et al. 2010). To allow for a comparison between FXBR and FLBR performance, two reactor columns were packed with the same amount of GAC, which resulted in an equivalent bed volume and EBCT (i.e., the initial EBCT of $42.8 \mathrm{~min}$ ) in the FXBR and FLBR systems.

As suggested by the reactor performance data (Figures 2 and 4), the use of $125 \mathrm{mg} / \mathrm{L} \mathrm{COD}$ of acetic acid allowed the establishment of a microbial community capable of nitrate and perchlorate reduction. Based on thermodynamic information for standard conditions and a $\mathrm{pH}$ of 7 , the expected order of TEAP zones is DO- $\left(\Delta \mathrm{G}^{\circ \prime}-844 \mathrm{~kJ} / \mathrm{mol}\right.$ acetate $)$, perchlorate- $(-801 \mathrm{~kJ} / \mathrm{mol}$ acetate), nitrate- $(-796 \mathrm{~kJ} / \mathrm{mol}$ acetate $)$, and sulfate- $(-52 \mathrm{~kJ} / \mathrm{mol}$ acetate) reducing zones (Chaudhuri et al. 2002, Rikken et al. 1996, Lovley \& Phillips 1988). Consistent with these values, a DO-reducing zone was expected at the inlet of the reactor, although DO was not monitored in the profile samples taken along the depth of the FXBR. Nitrate reduction started before perchlorate reduction (Figure 4), which is not consistent with the 
reported $\Delta \mathrm{G}^{\circ \prime}$ values. However, given that the $\Delta \mathrm{G}^{\circ \prime}$ values are for standard conditions and a $\mathrm{pH}$ of 7 , the much higher nitrate concentrations relative to perchlorate concentrations result in nitrate being a more favorable electron acceptor. DO and nitrate also regulate the expression of chlorite dismutase, a key enzyme in the perchlorate reduction pathway, and their presence thus inhibits perchlorate reduction (Chaudhuri et al. 2002). Concentration profiles within the biofilm, although not measured in the current study, also provide differential conditions promoting different TEAPs. The profile data indicated that nitrate- and perchlorate-reducing TEAP zones partially overlapped (Figure 4), suggesting that all these factors were important.

An equivalent amount of CBED COD (125 mg/L COD) did not result in similar contaminant removal performance compared with the acetic acid (Figure 2); this prompted the addition of more CBED COD, which was subsequently lowered. Acetate was present in the effluents of both reactors and was detected at higher levels when the CBED was provided in excess. It is likely that fermentation occurred in some parts of the bed, especially when sulfate reduction was more complete.

The electron donor limitation observed with the CBED was less pronounced in the FXBR than in the FLBR (Figure 2), possibly as a result of differences in hydraulic characteristics. Because of the high recycle ratio used for the FLBR, this system behaved close to a continuously stirred tank reactor, whereas the FXBR exhibited greater plug-flow characteristics. It is difficult to further explore this possibility at the laboratory-scale level because equivalent hydraulic loading rates (i.e., gallons per minute per square foot cross-sectional area) are needed to expand short laboratory-scale FLBR beds and tall commercial-scale FLBR beds. Higher recycle ratios are required for a short bed than for a tall bed at equivalent contaminant loading rates, resulting in recycle ratios at the laboratory-scale level that are not representative of those used in full-scale systems.

A longer EBCT was required for the FXBR operated with the CBED than with acetic acid to accomplish the same amount of nitrate and perchlorate removal (Figure 4). Visual changes in biomass characteristics and observed increases in biomass yield after changing the electron donor suggested a possible shift in microbial community structure. This could have resulted in less efficient removal of nitrate and perchlorate, leading to the need for a longer EBCT when the CBED was used.

Related to the optimization of EBCT is the need to evaluate the extent of sulfate reduction. When the CBED was used as the electron donor, most of the sulfate reduction occurred at and beyond port P8 (i.e., EBCT $>27 \mathrm{~min}$ ), when both nitrate and perchlorate were completely removed (Figure 4). Given that sulfate reduction results in the requirement of additional treatment downstream to remove odor and improve the aesthetic quality of the treated water, it is important to minimize sulfate reduction during drinking water treatment. For the conditions in the current study, lowering the EBCT to below $27 \mathrm{~min}$ in the FXBR could have minimized sulfate reduction. Alternatively, sulfate reduction could be minimized by controlling the ORP through the adjustment of acetic acid dose. Sulfate concentrations in groundwater are highly variable and often higher than evaluated in the current study. Given that considerable sulfate reduction was observed with higher electron donor dosing, electron donor dose controlling mechanisms-such as feed-forward and feed-backward systems (Brown et al. 2015) - need to be evaluated in a full-scale treatment system to limit sulfate reduction. With the feed-forward and feed-backward control mechanisms, the acetic acid dose will be adjusted on the basis of the bioreactor influent or effluent nitrate and perchlorate concentrations, respectively.

The limited available literature provided conflicting information on the comparative performance of FXBR and FLBR systems. Although the better performance observed in the FXBR compared with the FLBR in the current study was in disagreement with some previous observations (Rezaee et al. 2011, Borja \& Banks 1995, Holladay et al. 1978), a few studies have reported better performance in FXBR systems (Azizi et al. 2013, Clarke et al. 2007).

Biofilm development in a reactor is controlled by the flow characteristics. A more uniform and well-distributed biofilm may develop throughout an FLBR because of higher fluid shear (Rittmann 1982), whereas biofilm of variable thickness may develop in an FXBR as a result of greater plug-flow characteristics and comparatively less shear force of the liquid. In addition, biofilm development in an FXBR depends on the efficiency of biomass removal during backwashing. These considerations were of particular importance in the current study, especially given that the use of the CBED resulted in more biomass, which required a modification of the backwash protocol for the FXBR system.

An evaluation of the effect of backwashing on performance (Figure 5) indicated that effluent quality immediately after backwashing was excellent. Results obtained $1 \mathrm{~h}$ after backwashing reflected a dilution effect attributable to the use of DI water, which resulted in lower effluent concentrations (Upadhyaya et al. 2012). The total volume of the FXBR of $943 \mathrm{~cm}^{3}$ and an operational flow rate of $15 \mathrm{~mL} / \mathrm{min}$ indicate that approximately $1 \mathrm{~h}$ was required to completely flush out the liquid contained in the reactor after backwashing.

Visual observations and yield calculations suggested a higher biomass yield because of the change in electron donor. The observation of an increased biomass yield with the CBED is in agreement with previous research (Cherchi et al. 2009, DeBarbadillo et al. 2008). For example, operating laboratory-scale sequential batch reactors for denitrification of wastewater, Cherchi and colleagues (2009) reported yields of $0.29,0.35$, and $0.39 \mathrm{mg}$ volatile

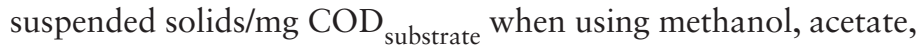
and the CBED, respectively. The increase in biomass yield because of the change in the electron donor resulted in the need for more frequent backwashing of the FXBR and cleaning of the FLBRdevelopments that require further evaluation in pilot-scale systems before the CBED is considered for full-scale drinking water treatment. Given that nitrite and ammonia are potential byproducts of nitrate reduction, these compounds also should be monitored during pilot-scale evaluation. Previous research has described the development and application of backwashing protocols in full-scale FXBR systems using similar electron donors resulting in high biomass yields (Ledwell et al. 2010). 


\section{CONCLUSION}

The CBED evaluated here supported the simultaneous removal of nitrate and perchlorate from drinking water using both the FXBR and FLBR systems. Approximately 20-35\% more CBED COD was required to achieve an effluent quality equivalent to that obtained with acetic acid. Compared with the FLBR, the FXBR was more robust and resilient to the effects of limited electron donor availability. The change in the electron donor resulted in a shift in biomass characteristics, which warrants further evaluation through microbial community and biofilm characterization, including characterization of extracellular polymeric substance components. The higher biomass generation and the more frequent maintenance required with the use of the CBED must be further evaluated in pilot- and full-scale systems before the product's commercial use.

\section{ACKNOWLEDGMENT}

The authors thank Xinsheng Chu and Ashley Hammerbeck for their help with chemical analyses and Shaw Environmental, Lawrenceville, N.J., for providing the perchlorate-reducing culture. This work was partially funded by Environmental Operating Solutions in Bourne, Mass., and the University of Michigan at Ann Arbor.

\section{ENDNOTES}

${ }^{1}$ MicroC $4000^{\mathrm{TM}}$, Environmental Operating Solutions, Bourne, Mass.

${ }^{2}$ F-816, Calgon Carbon, Pa.

${ }^{3}$ ENV471, Shaw Environmental, Lawrenceville, N.J.

${ }^{4}$ Fisher, Pittsburgh, $\mathrm{Pa}$.

${ }^{5}$ WTW Multi 340 with CellOx 325 sensors, WTW GmbH, Weilheim, Germany

${ }^{6}$ Oakton Instruments, Vernon Hills, Ill.

${ }^{7}$ SG2-SevenGo ${ }^{\text {TM }}$, Mettler Toledo, Columbus, Ohio

${ }^{8}$ Dionex, Sunnyvale, Calif.

${ }^{9}$ AS-16, Dionex, Sunnyvale, Calif.

${ }^{10} \mathrm{AG}-16$, Dionex, Sunnyvale, Calif.

${ }^{11}$ TOC-V CSH, Shimadzu, Columbia, Md.

${ }^{12}$ DR 4000, Hach, Loveland, Colo.

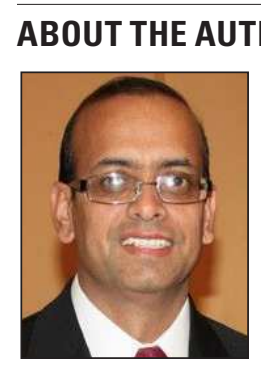

\section{HORS}

Giridhar Upadhyaya is a senior technologist with Carollo Engineers in Costa Mesa, Calif. He holds a bachelor's degree in engineering from Punjab Engineering College in Chandigarh, India, a master of science from Ghent University in Ghent, Belgium, and a doctorate from the University of Michigan in Ann Arbor, Mich. He has 23 years of experience in civil and environmental engineering and has been contributing to the field of biological drinking water treatment for the past 12 years. His research interests include biological removal of inorganic and organic contaminants (including arsenic, nitrate, perchlorate, hexavalent chromium, volatile organic compounds, microconstituents, and contaminants of emerging concern) as well as direct potable reuse. At the time this research was conducted, Upadhyaya was a post-doctoral research fellow in the Department of Civil and Environmental Engineering at the University of Michigan, Ann Arbor. Nadine Kotlarz is a doctoral student at the University of Michigan, Ann Arbor. Paul Togna is an independent consultant in Allentown, N.J.; at the time this research was conducted, he was chief technology officer at Environmental Operating Solutions, Bourne, Mass. Lutgarde Raskin (to whom correspondence may be addressed) is the Altarum/ERIM Russell O'Neal Professor of Engineering at the University of Michigan, Department of Civil and Environmental Engineering, 1351 Beal Ave., 107 EWRE, Ann Arbor, MI 48109 USA; raskin@umich.edu.

\section{PEER REVIEW}

Date of submission: 04/03/2015

Date of acceptance: 06/17/2015

\section{REFERENCES}

Akunna, J.C.; Bizeau, C.; \& Moletta, R., 1993. Nitrate and Nitrite Reductions With Anaerobic Sludge Using Various Carbon Sources: Glucose, Glycerol, Acetic Acid, Lactic Acid, and Methanol. Water Research, 27:8:1303.

Azizi, S.; Valipour, A.; \& Sithebe, T., 2013. Evaluation of Different Wastewater Treatment Processes and Development of a Modified Attached Growth Bioreactor as a Decentralized Approach for Small Communities. The Scientific World Journal, 1:1:1.

Benthack, C.; Srinivasan, B.; \& Bonvin, D., 2001. An Optimal Operating Strategy for Fixed-Bed Bioreactors Used in Wastewater Treatment. Biotechnology and Bioengineering, 72:1:34. http://dx.doi.org/10.1002/1097-0290(20010105) 72:1<34::AID-BIT5>3.0.C0;2-I.

Bill, K.A.; Bott, C.B.; \& Murthy, S.N., 2009. Evaluation of Alternative Electron Donors for Denitrifying Moving Bed Biofilm Reactors (MBBRS). Water Science and Technology: Journal of the International Association on Water Pollution Research, 60:10:2647.

Blanco, V.D.; Garcia, P.A.; \& Fdz-Polanco, F., 1995. Effects of Biofilm Growth, Gas, and Liquid Velocities on the Expansion of an Anaerobic Fluidized Bed Reactor (AFBR). Water Research, 29:7:1649.

Borja, R. \& Banks, C.J., 1995. Comparison of an Anaerobic Filter and an Anaerobic Fluidized Bed Reactor Treating Palm Oil Mill Effluent. Process Biochemistry, 30:6:511.

Brown, J.; Upadhyaya, G.; Cleveland, C.; Scheitlin, K.; Guysi, R.; Wu, P.; \& Chow, T., 2015. Two-Stage, Fixed-Bed Biological Treatment: Unlocking Contaminated Groundwater Resources. Proc. 2015 AWWA Annual Conference \& Exhibition, Anaheim, Calif.

Brown, J. \& Lauderdale, C.V., 2006. Efficient, Simultaneous Destruction of Multiple Drinking Water Contaminants Using Biological Filtration. Florida Water Resources Journal, 3:28.

Brown, J.; Anderson, R.D.; Min, J.H.; Boulos, L.; Prasifka, D.; \& Juby, G.J.G., 2005. Fixed-Bed Biological Treatment of Perchlorate-Contaminated Drinking Water. Journal AWWA, 97:9:70.

Brown, J.; Snoeyink, V.L.; Raskin, L.; \& Lin, R., 2003. The Sensitivity of Fixed-Bed Biological Perchlorate Removal to Changes in Operating Conditions and Water Quality Characteristics. Water Research, 37:1:206.

Chaudhuri, S.K.; O'Connor, S.M.; Gustavson, R.L.; Achenbach, L.A.; \& Coates, J.D., 2002. Environmental Factors That Control Microbial Perchlorate Reduction. Applied and Environmental Microbiology, 68:9:4425.

Cherchi, C.; Onnis-Hayden, A.; El-Shawabkeh, I.; \& Gu, A.Z., 2009. Implication of Using Different Carbon Sources for Denitrification in Wastewater Treatments. Water Environment Research, 81:8:788.

Choi, H. \& Silverstein, J.A., 2007. Effluent Recirculation to Improve Perchlorate Reduction in a Fixed Biofilm Reactor. Biotechnology and Bioengineering, 98:1:132.

Clarke, K.; Gordon, A.H.; \& Pugsley, T.S., 2007. Direct Comparison of Fluidized Bed and Packed Bed Bioreactors for Bioremediation of an Air Pollutant. International Journal of Chemical Reactor Engineering, 5:1:1.

DeBarbadillo, C.; Miller, P.; \& Ledwell, S., 2008. A Comparison of Operating Issues and Dosing Requirements for Alternative Carbon Sources in Denitrification 
Filters. Proc. 2008 Water Environment Federation 81st Annual Conference and Exposition, Chicago. http://dx.doi.org/10.2175/193864708790893585.

Dugan, N.R.; Williams, D.J.; Meyer, M.; Schneider, R.R.; Speth, T.F.; \& Metz, D.H., 2009. The Impact of Temperature on the Performance of Anaerobic Biological Treatment of Perchlorate in Drinking Water. Water Research, 43:7:1867.

Fuller, M.E.; Hatzinger, P.B.; Condee, C.W.; \& Togna, A.P., 2007. Combined Treatment of Perchlorate and RDX in Ground Water Using a Fluidized Bed Reactor. Groundwater Monitoring \& Remediation, 27:3:59.

Hach, 2014. Oxygen Demand, Chemical. Method 8000. Hach, Loveland, Colo.

Hamlin, H.J.; Michaels, J.T.; Beaulaton, C.M.; Graham, W.F.; Dutt, W.; \& Steinbach, P., 2008. Comparing Denitrification Rates and Carbon Sources in Commercial Scale Upflow Denitrification Biological Filters in Aquaculture. Aquaculture Engineering, 38:2:79.

Holladay, D.W.; Hancher, C.W.; Scott, C.D.; \& Chilcote, D.D., 1978. Biodegradation of Phenolic Waste Liquors in Stirred-Tank, Packed-Bed, and Fluidized-Bed Bioreactors. Journal Water Pollution Control Federation, 50:11:2573.

Kimbrough, D.E. \& Parekh, P., 2007. Occurrence and Co-occurrence of Perchlorate and Nitrate in California Drinking Water Sources. Journal AWWA, 99:9:126.

Kurt, M; Dunn, I.J.; \& Bourne, J.R., 1987. Biological Denitrification of Drinking Water Using Autotrophic Organisms With H2 in a Fluidized-Bed Biofilm Reactor. Biotechnology and Bioengineering, 29:4:493.

Ledwell, S.; Fabiyi, M.; \& Farmer, G., 2010. Optimizing Denitrification With Nonmethanol Carbon Sources in Deep-Bed Denitrification Filter Technologies. Proc. 2010 Water Environment Federation Technical Exhibition and Conference, New Orleans, La. http://dx.doi.org/10.2175/193864710798157879.

Li, X.; Upadhyaya, G.; Yuen, W.; Brown, J.; Morgenroth, E.; \& Raskin, L., 2010. Changes in the Structure and Function of Microbial Communities in Drinking Water Treatment Bioreactors Upon Addition of Phosphorus. Applied and Environmental Microbiology, 76:22:7473.

Logan, B.E. \& LaPoint, D., 2002. Treatment of Perchlorate- and NitrateContaminated Groundwater in an Autotrophic, Gas Phase, Packed-Bed Bioreactor. Water Research, 36:14:3647.

Lovley, D.R. \& Phillips, E.J., 1988. Novel Mode of Microbial Energy Metabolism: Organic Carbon Oxidation Coupled to Dissimilatory Reduction of Iron or Manganese. Applied and Environmental Microbiology, 54:6:1472.

McCarty, P.L. \& Meyer, T.E., 2005. Numerical Model for Biological Fluidized-Bed Reactor Treatment of Groundwater. Environmental Science \& Technology, 39:3:850.

Mohseni-Bandpi, A. \& Elliott, D.J., 1998. Groundwater Denitrification With Alternative Carbon Sources. Water Science and Technology, 38:6:237.

NSF International, 2015. NSF Product and Service Listings. NSF/ANSI 60. Drinking Water Treatment Chemicals-Health Effects. Miscellaneous Water Supply Products. Trade Designation MicroC 4000TM. http://info.nsf.org/Certified/ PwsChemicals/Listings.asp?Company=C0072916\&Standard=060 (accessed Sept. 23, 2015).
Patel, A.; Zuo, G.; Lehman, S.G.; Badruzzaman, M.; Clifford, D.A.; \& Roberts, D.J., 2008. Fluidized Bed Reactor for the Biological Treatment of Ion-Exchange Brine Containing Perchlorate and Nitrate. Water Research, 42:16:4291.

Pretorius, C.; Kilian, R.; \& Jannone, J., 2006. Give Your Denitrification Bugs a Sugar High. Proc. 2006 Water Environment Federation Technical Exhibition and Conference, Dallas. http://dx.doi.org/10.2175/193864706783751852.

Ravnjak, M.; Vrtovšek, J.; \& Pintar, A., 2013. Denitrification of Drinking Water in a TwoStage Membrane Bioreactor by Using Immobilized Biomass. Bioresource Technology, 128:804. http://dx.doi.org/10.1016/j.biortech.2012.10.055.

Rezaee, A.; Jorfi, S.; \& Soltani, R.D., 2011. Comparison of the Efficiency of Movingand Fixed-Bed Bioreactors for Treatment of High-Strength Synthetic Wastewater. Chemical \& Biochemical Engineering Quarterly, 25:4:445.

Ricardo, A.R.; Carvalho, G.; Velizarov, S.; Crespo, J.G.; \& Reis, M.A.M., 2012. Kinetics of Nitrate and Perchlorate Removal and Biofilm Stratification in an Ion Exchange Membrane Bioreactor. Water Research, 46:14:4556.

Rikken, G.; Kroon, A.; \& Van Ginkel, C., 1996. Transformation of (Per) Chlorate Into Chloride by a Newly Isolated Bacterium: Reduction and Dismutation. Applied Microbiology and Biotechnology, 45:3:420.

Rittmann, B.E., 1982. Comparative Performance of Biofilm Reactor Types. Biotechnology and Bioengineering, 24:6:1341.

Rittmann, B.E., \& McCarty, P.L., 2001. Environmental Biotechnology: Principles and Applications. McGraw-Hill, New York.

Tziotzios, G.; Dermou, E.; Politi, D.; \& Vayenas, D.V., 2008. Simultaneous Phenol Removal and Biological Reduction of Hexavalent Chromium in a Packed-Bed Reactor. Journal of Chemical Technology and Biotechnology, 83:6:829.

Upadhyaya, G.; Clancy, T.M.; Snyder, K.V.; Brown, J.; Hayes, K.F.; \& Raskin, L., 2012. Effect of Air-Assisted Backwashing on the Performance of an Anaerobic Fixed-Bed Bioreactor That Simultaneously Removes Nitrate and Arsenic From Drinking Water Sources. Water Research, 46:1309. http://dx. doi.org/10.1016/j.watres.2011.12.034.

Upadhyaya, G.; Jackson, J.; Clancy, T.M.; Hyun, S.P.; Brown, J.; Hayes, K.F.; \& Raskin, L., 2010. Simultaneous Removal of Nitrate and Arsenic From Drinking Water Sources Utilizing a Fixed-Bed Bioreactor System. Water Research, 44:17:4958

USEPA (US Environmental Protection Agency), 2011. Drinking Water: Regulatory Determination on Perchlorate. Federal Register, 76:29:7762.

USEPA, 2008. Interim Drinking Water Health Advisory for Perchlorate. EPA 822-R08-025. USEPA Office of Water, Washington.

Water Research Foundation, 2011. State-of-Science on Perchlorate Treatment Technologies and Regulations. Water Research Foundation, Denver.

Webster, T.S.; Guarini, W.J.; \& Wong, H.S., 2009. Fluidized Bed Bioreactor Treatment of Perchlorate-Laden Groundwater to Potable Standards. Journal AWWA, 101:5:137.

Zhao, H.; Ginkel, S.V.; Tang, Y.; Kang, D.; Rittmann, B.E.; \& Brown, R.K., 2011. Interactions Between Perchlorate and Nitrate Reductions in the Biofilm of a Hydrogen-Based Membrane Biofilm Reactor. Environmental Science \& Technology, 45:23:10155 